\title{
Indução de fitoalexinas em cotilédones de soja em resposta a derivados de folhas de pitangueira
}

\author{
Induction of phytoalexins in cotyledons of soybean in response to the derivatives of leaf surinan cherry
}

\author{
Sergio Miguel Mazaro' Idemir Citadin"I Alfredo De GouvêaIII Daiane Luckmann ${ }^{\text {III }}$ \\ Sabrina Santos Guimarães ${ }^{\text {III }}$
}

\section{RESUMO}

A demanda mundial por alimentos isentos de agrotóxicos tem impulsionado a pesquisa para a busca de métodos alternativos ao controle de patógenos em plantas. A ativação dos mecanismos de defesa com o uso de indutores vem demonstrando ser uma alternativa viável e promissora. $O$ uso de extratos de plantas medicinais tem demonstrado capacidade para induzir a produção de fitoalexinas, como um mecanismo de defesa em plantas tratadas. O objetivo deste trabalho foi verificar o potencial da planta Eugenia uniflora $L$. (pitangueira) em induzir fitoalexinas em cotilédones de soja (Glycine max). Os derivados de extrato alcoólico, infusão, maceração e decocção, obtidos de folhas de pitangueira, foram usados nas concentrações de 0,1; $1 ; 10$ e 40\%, além de óleo essencial. Água foi utilizada como controle e quitosana (1\%) como indutor de referência. Os preparados de pitangueira apresentaram capacidade de indução das fitoalexinas gliceolinas em cotilédones de soja, respondendo ao aumento das concentrações dos preparados. O óleo essencial apresentou destacável efeito na indução de fitoalexinas, sendo superior aos demais preparados. Quitosana induziu fitoalexinas em cotilédones de soja e pode ser utilizado em estudos similares como um indutor de referência.

Palavras-chave: gliceolina, indução de resistência, plantas medicinais.

\section{ABSTRACT}

The worldwide demand for food without pesticides has stimulated the research on alternative methods to control pathogens in plants. The activation of defense mechanisms by inductors seems a viable and promising alternative. The use of medicinal plants extracts has demonstrated capacity to induce the production of phytoalexins, as a mechanism of defense in treated plants. The objective of this research was to verify the potential of Eugenia uniflora L. (surinan cherry) to induce phytoalexins in cotyledons of soybean (Glycine max). The derivatives alcoholic extract, infusion, maceration and decoction, obtained of surinan cherry were used in the concentrations of $0.1 ; 1 ; 10$ and 40\%, beyond essential oil. Water was used for the control and chitosan (1\%) as inductor reference. The preparations of surinan cherry presented capacity of induction of the phytoalexins glyceolin in cotyledons of soybean, with the increasing concentration of the preparations. The essential oil presents detachable effect in the induction of phytoalexins in relation to the other preparations. Chitosan induces phytoalexins in cotyledons soybean and can be used in similar studies as a reference inductor.

Key words: glyceolin, induction of resistance, medicinal plants.

\section{INTRODUÇÃO}

A produção de alimentos mais saudáveis, isentos de resíduos tóxicos, vem sendo enfatizada nos últimos anos e, com isso, vários trabalhos são realizados com métodos de controle alternativos de fitopatógenos (JANISIEWICZ, 1996; FRANCO \& BETTIOL, 2000; CAMPANHOLA \& BETTIOL, 2003). A indução de resistência em plantas a patógenos com a utilização de elicitores é relatada em diferentes culturas (LOPEZ, 1991; PICCINI, 1995; SATHIYABAMA \& BALASUBRAMANIAN, 1998; HEIL \& BOSTOCK, 2002; TERRY \& JOYCE, 2004) e pode ser conceituada como um mecanismo de defesa induzida por agentes bióticos ou abióticos que confere

\footnotetext{
'Laboratório de Bioquímica e Fitossanidade, Universidade Tecnológica Federal do Paraná (UTFPR), Campus Dois Vizinhos, Estrada para Boa Esperança, Km 04, 85660-000, Dois Vizinhos, PR, Brasil. E-mail:sergio@utfpr.edu.br. Autor para correspondência. ${ }^{\text {IIC }}$ urso de Agronomia, UTFPR, Campus Pato Branco, Pato Branco, PR, Brasil.

IIIUTFP, Campus Dois Vizinhos, Dois vizinhos, PR, Brasil.
} 
proteção à planta a um amplo espectro de microorganismos (DURRANT \& DONG, 2004).

Diversos trabalhos mostram o potencial de plantas medicinais no controle de fitopatógenos, tanto por sua ação fungitóxica direta, inibindo o crescimento micelial e a germinação de esporos, quanto pela capacidade de induzir o acúmulo de fitoalexinas, indicando a presença de moléculas com características elicitoras (BONALDO et al., 2004). A Eugenia uniflora L. (pitangueira), pertence à família Myrtaceae, é uma planta de frutos comestíveis muito conhecida e apreciada no Brasil e o chá de suas folhas tem aplicação na medicina popular, principalmente como hipotensor, antigota, estomáquico e hipoglicemiante. Em estudos realizados sobre as propriedades farmacobotânicas, químicas e farmacológicas de folhas de pitangueira, foram encontrados, no óleo essencial, diversos compostos como sesquiterpenos, compostos fenólicos, alcalóides, entre outros grupos, com atividade antimicrobiana (AURICCHIO \& BACCHI, 2003). Essa diversidade de metabólitos secundários presentes na pitangueira podem apresentar potencial para utilização de compostos da planta na agricultura para ativação de rotas de defesa, com ativação de metabólitos como as fitoalexinas.

As fitoalexinas são metabólitos secundários, antimicrobianos, produzidos pela planta em resposta a estresses físicos, químicos ou biológicos. O modo de ação sobre fungos inclui granulação citoplasmática, desorganização dos conteúdos celulares, ruptura da membrana plasmática e inibição de enzimas fúngicas, refletindo na inibição da germinação e na elongação do tubo germinativo e na redução ou na inibição do crescimento micelial. As fitoalexinas possuem grande diversidade, sendo que mais de 300 tipos já foram caracterizados entre diferentes classes de compostos químicos, como cumarinas, diterpenos, flavonóides, luteolinidina, apigenidina e apigeninidina (CAVALCANTI et al., 2005).

A primeira fitoalexina caracterizada quimicamente foi a pisatina, isolada de plantas de ervilha (Pisum sativum), sendo que desde sua descoberta inúmeras outras fitoalexinas foram obtidas de plantas cultivadas como feijão, soja, ervilha, batata, tomate, alface, algodão, arroz, cevada, banana, entre outras (BRAGA, 2007).

Em soja, a fitoalexina gliceolina (pterocarpanóide) mostra-se importante na interação dessa leguminosa com fitopatógenos, sendo que a utilização de cotilédones de soja mostrou-se como excelente ferramenta para estudos envolvendo ação elicitora de moléculas de origem biótica e abiótica (SCHWAN-ESTRADA et al., 2000).

Apesar de mais de 300 fitoalexinas já terem sido isoladas, menos de $1 \%$ dos vegetais superiores foi analisado quanto à capacidade de produzir essas substâncias, sendo em sua maioria espécies cultivadas pelo homem. Assim, o estudo e a síntese de fitoalexinas, especialmente em espécies nativas, abre enormes perspectivas para descoberta de novos produtos naturais com atividade antimicrobiana e cujas estruturas podem servir como modelo para a síntese química de defensivos agrícolas naturais (BRAGA, 2007). A utilização de extrato bruto e óleo essencial de pitangueira na indução de fitoalexinas em cotilédones de soja já foram observados por SCHWAN-ESTRADA et al., 2000), porém, carece de conhecimentos sobre o efeito de extrato alcoólico, decocção, infusão e maceração, além do efeito de concentrações sobre a resposta na produção de fitoalexinas.

A quitosana possui ação indutora comprovada e pode ser utilizada como um indutor de referência em estudos de indução a fitoalexinas. É um produto orgânico, obtido a partir da reação de desacetilação parcial da quitina, substância essa encontrada em invertebrados marinhos, insetos, fungos e leveduras (MATHUR \& NARANG, 1990). O uso de quitosana na agricultura está tomando importância pela sua atividade elicitora sobre uma enorme gama de plantas. A quitosana atua na Resistência Sistêmica Adquirida (RSA), realçando a transcrição e a tradução de genes de defesa (AGRAWAL et al., 2002), a ativação de proteínas relacionadas à patogenicidade (SATHIYABAMA \& BALASUBRAMANIAN, 1998), altera o metabolismo das fitoalexinas (TERRY \& JOYCE, 2004) e induz a formação de compostos fenólicos (BAUTISTA-BAÑOS et al., 2006).

O objetivo deste trabalho foi avaliar o potencial de diferentes preparados de pitangueira em ativar mecanismos de defesa em plantas por meio da produção de fitoalexinas em cotilédones de soja.

\section{MATERIAL E METODOS}

O experimento foi conduzido em 2007, no Laboratório de Fitossanidade e Bioquímica da Universidade Tecnológica Federal do Paraná (UTFPR),

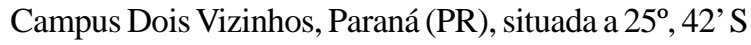
e $53^{\circ}, 03^{\prime}$ W, a 519 metros de altitude. As folhas foram coletadas em plantas nativas pertencentes a reserva legal da UTFPR - Dois Vizinhos. Após terem sido lavadas, pesadas e eliminadas aquelas com danos ou lesões, foram realizados os diferentes preparados. Os tratamentos foram constituídos de extrato alcoólico, decocção, infusão e maceração nas concentrações de 0,1; 1, 10 e 40\%, óleo essencial (100\%), quitosana (indutor de referência) e água (controle). Para infusão, a água destilada foi fervida previamente e logo após 
foram adicionadas as folhas desidratadas da planta, deixando-se agir por 20min em recipiente fechado. $\mathrm{Na}$ decocção, as folhas foram colocadas em água destilada fria, aquecendo até a ebulição e deixando ferver por cinco minutos e, em seguida, elas foram reservadas em recipiente por 20min. Para o preparo da maceração as folhas foram maceradas em água fria destilada e foram reservadas em recipiente por oito horas. A extração alcoólica foi obtida por meio de imersão das folhas em etanol absoluto por dez dias, na ausência de luz, e então o etanol foi extraído por meio de evaporador rotativo por quatro horas a temperatura de $60^{\circ} \mathrm{C}$. O óleo essencial foi obtido por meio da técnica de arraste de vapor por hidrodestilação, durante quatro horas, em aparelho graduado tipo clevenger (WASICKY, 1963). A quitosana foi dissolvida em ácido acético 1\%, após completa diluição, foi acrescentada água destilada para obter a concentração de $1 \%$.

Sementes de soja da cultivar "COODETEC 205” foram plantadas em gerbox, contendo areia autoclavada, e foram mantidas em casa de vegetação. Após dez dias, os cotiledones das plântulas foram removidos e lavados com água destilada. Na face abaxial dos cotilédones, foi feito um corte superficial e sobre esse corte depositados 40uL da solução elicitora ou de água destilada. Os cotilédones foram pesados e então colocados em placas de petri (quatro por placa) forradas com disco de papel de filtro umedecidos com água destilada. As placas tampadas e não-vedadas foram mantidas em BOD a $26^{\circ} \mathrm{C}$, no escuro. Após 20 horas, os cotiledones foram retirados das placas e colocados em tubos plásticos contendo $10 \mathrm{~mL}$ de água destilada e então estes tubos foram agitados em mesa agitadora por uma hora para a extração de gliceolina. A solução foi filtrada em papel de filtro Whatman no41 e a absorbância foi determinada em espectofotômetro em comprimento de onda de $285 \mathrm{~nm}$, de acordo com metodologia descrita por LABANCA (2002).

Os ensaios foram desenvolvidos em delineamento experimental inteiramente casualizado com quatro repetições. Os resultados obtidos foram submetidos à avaliação de homogeneidade pelo teste de Bartlett a 5\% de probabilidade de erro (STEEL et al., 1997). Para os compostos que possibilitaram avaliar concentrações (extrato alcoólico, infusão, decocção e maceração), foram feitas análises de regressões pelo programa de análise estatística SANEST (ZONTA \& MACHADO, 1984). A melhor resposta dos tratamentos obtidos por regressão foi comparação com a testemunha (água), indutor referência (quitosana) e óleo essencial por meio de análise de variância e comparação de médias pelo teste de Tukey a 5\% de probabilidade de erro, com o software SASM Agri (ALTHAUS et al., 2001).

\section{RESULTADOS E DISCUSSÕES}

Os diferentes preparados de pitangueira possuem ação na indução das fitoalexinas gliceolinas em cotiledones de soja (Figura 1A, 1B, 1C e 1D), sendo esse efeito caracterizado com o aumento das concentrações dos preparados e entre as concentrações avaliadas, sendo que as que apresentaram maior resposta foram para extrato alcoólico nas concentrações de dez e 40\% (Figura 1A), infusão na concentração de 40\% (Figura 1B), decocção na concentração de $40 \%$ (Figura 1C) e maceração nas concentrações de10 e 40\% (Figura 1D). As regressões realizadas demonstraram haver um efeito concentraçãodependente, sendo que para infusão, decocção e maceração foi expressa pela equação linear, com $r^{2}$ variando de 0,82 a 0,95 e para extrato alcoólico expressa por uma equação quadrática, com $\mathrm{r}^{2}$ de 0,69 . Isso demonstra que os preparados possuem diferentes capacidades de extração dos metabólitos e que as substâncias elicitoras de indução estão relacionadas com a maior concentração dessas substâncias. Utilizando diferentes concentrações $(0,1 ; 1 ; 5 ; 10 ; 15$; 20 e 25\%) de extrato de eucalipto, BONALDO et al. (2004) demonstraram que a produção de fitoalexinas deoxiantocianidinas em mesocótilos de sorgo foi mais expressiva nas concentrações acima de $10 \%$ e gliceolina em cotilédones de soja acima de $15 \%$. Em pitangueira e em diversas espécies como cânfora, poejo, romã e cardo-santo, também foram observados maior síntese de fitoalexinas em concentrações mais elevadas desses extratos (STANGARLIN et al., 1999).

No processo de interação dos elicitores com a planta, ocorre o estabelecimento de uma série de resposta envolvendo liberação de sinais moleculares, iniciando pelo reconhecimento ou pela percepção, pela transdução do sinal e pela tradução para a ativação de genes de defesa (BOSTOCK, 2005). Possivelmente, concentrações elevadas façam com que a percepção de sinais derivados do elicitor seja mais eficiente, causando alterações no metabolismo celular, como ativação de proteínas $\mathrm{G}$, aumento no fluxo de íons por meio da membrana plasmática, atividade de quinases e fosfatases e produção de mensageiros secundários (LEITE et al., 1997; CAVALCANTI et al., 2005), ativando rotas metabólicas como a síntese de fitoalexinas.

O óleo essencial apresentou destacável capacidade de indução de fitoalexinas, sendo superior aos melhores resultados dos diferentes preparados e até mesmo da quitosana (Figura 2). Nos óleos essenciais, podem ocorrer diversas substâncias orgânicas com capacidade de indução de resistência, como hidrocarbonetos terpênicos, álcoois simples e 


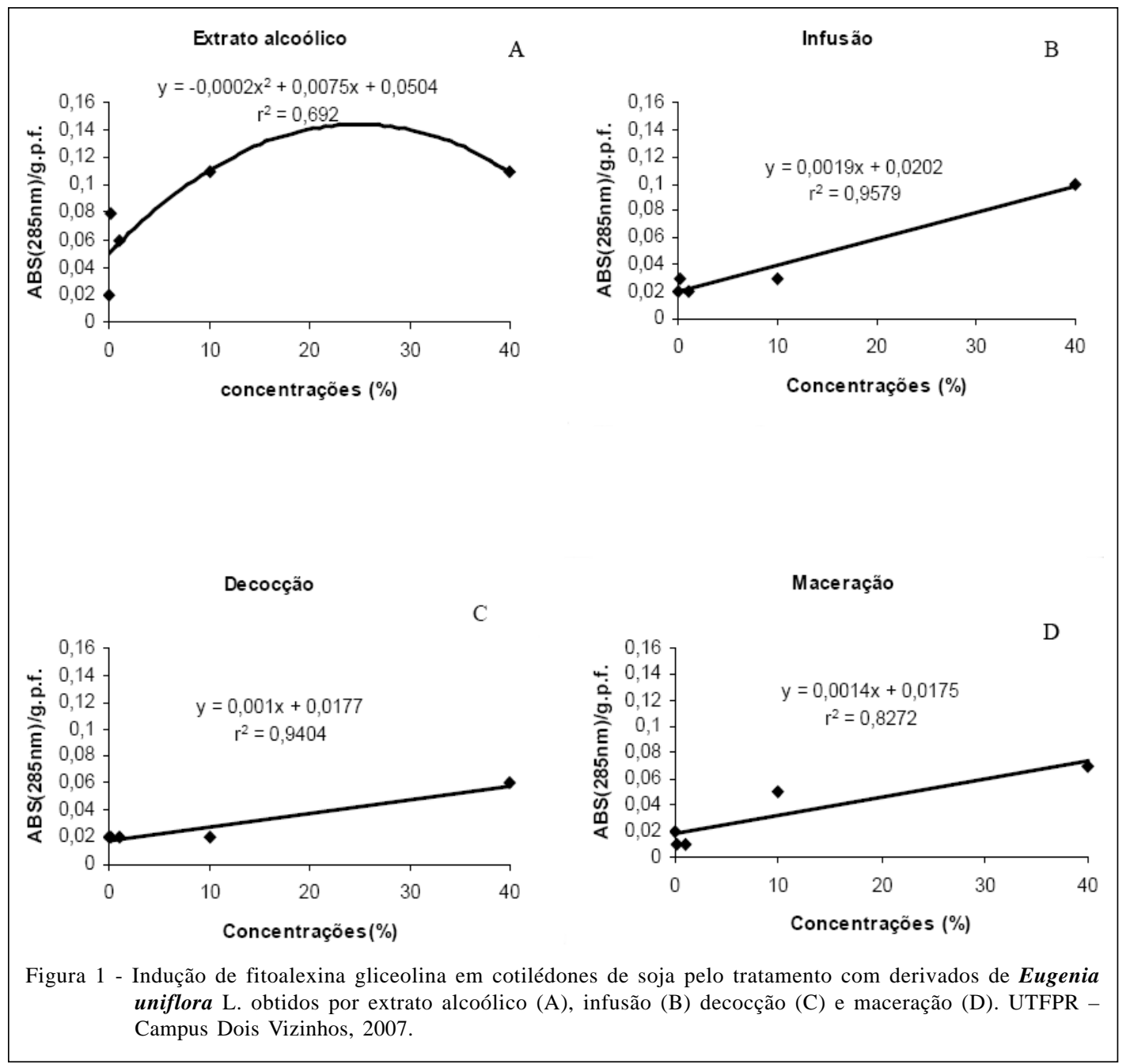

terpênicos, aldeídos, cetonas, fenóis, ésteres, éteres, óxidos, peróxidos, furanos, ácidos orgânicos, lactonas, cumarinas, até compostos contendo enxofre (DEWICK, 1997). Em folhas de E. uniflora, o composto furanodieno e seu produto de rearranjo, furanoelemeno ou curzereno (50,2\%), ß-elemeno (5,9\%) e a-cadinol $(4,7 \%)$ foram os constituintes majoritários (MELO et al., 2007). Possivelmente o óleo essencial, pela forma de obtenção e por ser um produto concentrado, apresente maior diversidade e concentração de substâncias com ação elicitora.

No controle, no qual foi aplicada água, ocorreu uma pequena indução da produção de fitoalexinas (Figura 2). Isso possivelmente seja devido à produção destas, induzidas pela lesão mecânica realizada nos cotilédones, sendo que as fitoalexinas são metabólitos secundários, antimicrobianos, produzidos pela planta em resposta a estresses físicos, químicos ou biológicos (CAVALCANTI et al., 2005).
Em relação ao tratamento com quitosana, utilizado como indutor referência, o produto mostrou grande capacidade de induzir a produção de fitoalexinas, sendo superior a todos os preparados, com exceção do óleo essencial (Figura 2). Tal resultado veio reafirmar sua capacidade de alteração no metabolismo das fitoalexinas (TERRY \& JOYCE, 2004) e pode ser utilizado como um indutor de referência em estudos de indução a fitoalexinas em cotilédones de soja.

Uma avaliação conjunta dos resultados nos permite afirmar que compostos à base de pitangueira apresentam potencial de utilização no controle alternativo de patógenos em plantas. A forma de extração pode ser infusão, decocção e maceração, com a possibilidade de isolamento industrial das substâncias elicitoras, permitindo o desenvolvimento de produtos naturais, não-agressivos ao homem e ao ambiente.

Trabalhos futuros devem ser desenvolvidos, buscando avaliar a potencialidade desses compostos 


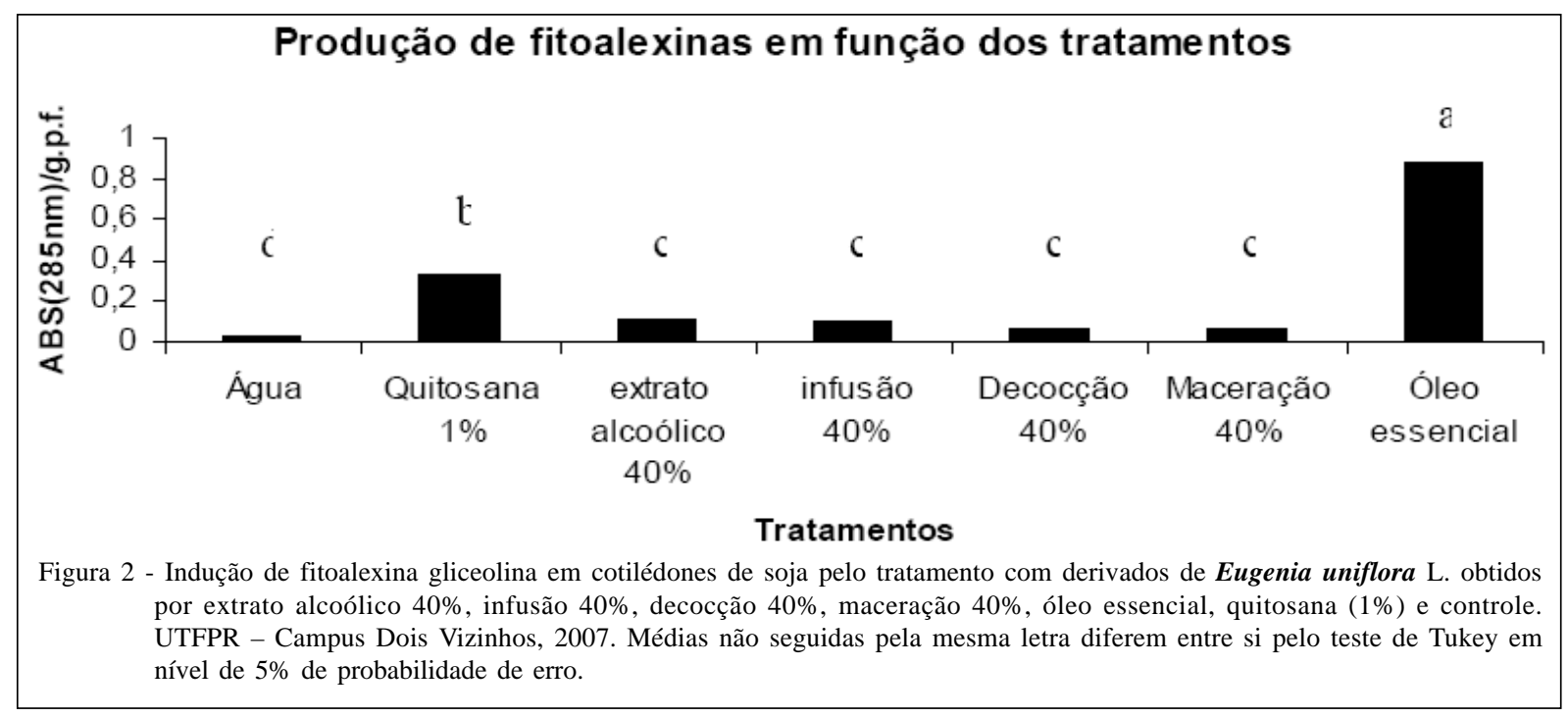

à base de pitangueira, em diferentes patossistemas, como verificado na proteção de pepinos contra Colletotrichum lagenarium pelo uso de extrato de Eucalyptus citriodora (BONALDO, et al., 2004).

\section{CONCLUSÕES}

Os preparados de Eugenia uniflora possuem potencial para induzir as fitoalexinas gliceolinas em cotiledones de soja, respondendo ao aumento das concentrações dos preparados. O óleo essencial apresentou destacável efeito na indução de fitoalexinas, sendo superior aos demais preparados. Quitosana induziu fitoalexinas gliceolinas em cotilédones de soja e pode ser utilizado em estudos similares como um indutor de referência.

\section{REFERÊNCIAS}

AGRAWAL, G.K. et al. Chitosan activates defese/stress response(s) in the leaves of Oryza sativa seeddlings. Plant Physiology and Biochemistry, v.40, n.12, p.1061-1069, 2002.

ALTHAUS, R.A. et al. Tecnologia da informação aplicada ao agronegócio e ciências ambientais: sistema para análise e separação de médias pelos métodos de Duncan, Tukey e ScottKnott. ENCONTRO ANUAL DE INICIAÇÃO CIENTÍFICA, 10., 2001, Ponta Grossa, PR. Anais... Ponta Grossa, 2001. Parte 1, p.280-281, 2001.

AURICCHIO, M.T.; BACCHI, E.M. Folhas de Eugenia uniflora L. (pitangueira): propriedades farmacobotânicas, químicas e farmacológicas. Revista do Instituto Adolfo Lutz, v.62,n.1, p.55-61, 2003.

BAUTISTA-BAÑOS, S. et al. Chitosan as a potential natural compound to control pre and postharvest diseases of horticultural commodities. Crop Protection, v.25, p.108$118,2006$.
BONALDO, S.M. et al. Fungitoxidade, atividade elicitora de fitoalexinas e proteção de pepino contra Colletotrichum lagenarium, pelo extrato aquoso de Eucalyptus citriodora. Fitopatologia Brasileira, v.29, p.128-134, 2004.

BOSTOCK, R.M. Signal crosstalk and induced resistance: Straddling the between cost and benefit. Annual Review of Phytopathology, v.43, p.545-580, 2005.

BRAGA, M.R. Fitoalexinas e a defesa das plantas. Acesso em 23/jul/2007. On line. Disponível na Internet: www.sbq.org.br/ PN-NET/texto5/defesa.htm.

CAMPANHOLA, C.; BETTIOL, W. Métodos alternativos de controle fitossanitário. Jaguariúna: EMBRAPA Meio ambiente, 2003. 279p.

CAVALCANTI, L.S. et al. Aspectos bioquímicos e moleculares da resistência induzida. In: CAVALCANTI, L.S. et al. (Eds.). Indução de resistência em plantas a patógenos e insetos. Piracicaba: FEALQ, 2005. p.81-124.

DEWICK, P.M. Medicinal natural products: a biosynthetic approach. Chichester: John Wiley \& Sons, 1997. 520p.

DURRANT, W.E.; DONG X. Systemic acquired resistance. Annual Review of Phytopathology, v.42, p.185-209, 2004.

FRAnCO, D.A.S.; BetTIOL, W. Controle de Penicillium digitatum em pós-colheita de citros com produtos alternativos. Fitopatologia Brasileira, v.25, p.602-606, 2000.

HEIL, M.; BOSTOCK, M.R. Induced systemic resistance (ISR) against pathogens in the context of induced plant defences. Annals of Botany, v.89, p.503-512, 2002.

JANISIEWICZ, W.J. Ecological diversity, niche overlap, and coexistance of antagonist used in developing mixtures for ciocontrol of postharvest diseases of apples. Phytopathology, v.86, p.473-479, 1996. 1996.

LABANCA, E.R.G. Purificação parcial de elicitores presentes em Saccharomyces cerevisiae: atividade como

Ciência Rural, v.38, n.7, out, 2008. 
indutores de resistência em pepino (Cucumis sativus) contra Colletotrichum lagenarium e da síntese de gliceolinas em soja (Glycine max). 2002. 107f. Dissertação (Mestrado) - Escola Superior de Agricultura. "Luiz de Queiroz", Universidade de São Paulo.

LEITE, B. et al. Reconhecimento e transdução de sinais moleculares em interações planta-fungos patogênicos. Revisão Anual de Patologia de Plantas, v.5, p.235-280, 1997.

LOPEZ, A.M.Q. Controle alternativo da antracnose causada por Colletotrichum graminicola (Ces.) Wils. Em sorgo (Sorghum bicolor L. (Moench). 1991. $203 \mathrm{f}$. Dissertação (Mestrado) - Faculdade Estadual Paulista "Júlio de Mesquita”.

MATHUR, N. K.; NARANG, C.K. Chitin and chitosan, versatile polysaccharides from marine animals. Journal of Chemical Education, v.67, p.938-942, 1990.

MELO, R.M. et al. Identification of impact aroma compounds in Eugenia uniflora L. (Brazilian Pitanga) leaf essential oil. Journal Brazilian Chemmical Society, v.18, n.1, p.179183, 2007.

PICCINI, E. Uso de Saccharomyces cerevisiae na proteção de plantas de sorgo (Sorghum bicolor), maracujá azedo amarelo (Passiflora edulis) e eucalipto (Eucalyptus spp.) contra fitopatógenos fúngicos e bacterianos. 1995. $107 \mathrm{f}$. Dissertação (mestrado) - Escola Superior de Agricultura. "Luiz de Queiroz”, Universidade de São Paulo.
SATHIYABAMA M.; BALASUBRAMANIAN, R. Chitosan induces resistence components in Arachis hypogaea leaf rust caused by Puccinia arachidis Speg. Crop Protection, v.17, n.4, p.307-313, 1998

SCHWAN-ESTRADA, K.R.F. et al. Uso de extratos vegetais no controle de fungos fitopatogênicos. Floresta, v.30, n.1-2, p.129-137, 2000.

STANGARLIN, J.R. et al. Plantas medicinais e controle alternativo de fitopatógenos. Biotecnologia Ciência \& Desenvolvimento, v.11, p.16-21. 1999.

STEEL, R.G.D. Principles and procedures of statistics: a biometrical approach. 3.ed. Nova York: McGraw-Hill, 1997. 666p.

TERRY, L.A.; JOYCE, D.C. Elicitors of induced disease resistance in posharvest horticultural crops: a brief review. Postharvest Biology and Technoly, v.32, p.1-13, 2004.

WASICKY, R. Uma modificação do aparelho de clevenger para extração de óleos essenciais. Faculdade de farmácia e bioquímica, São Paulo, v.1, n.1, p.77-81, 1963.

ZONTA, E.P.; MACHADO A.A. Sistema de análise estatística para microcomputadores - SANEST. Pelotas: UFPel, Instituto de Física e Matemática, 1984. 150p. 